black and whte card moved horizontally in front of the eyes. The estimates that I have made with proper apparatus very closely correspond with the value as originally determined by Charpentier. With a disc revolving once in two seconds, I fitd the apparent anguar magnitudes of the two phases equal to about $2^{\circ} .5$; with a disc revolving twice as fast they are about $5^{\circ}$.

(2) Charfentier's experiment of the Fluted Band is somewhat more difficult of performance and of interpretation. A black disc, $45 \mathrm{~cm}$. in diameter, revolving about twice per second, with a small white spot $(1 \mathrm{~cm} . \times \cdot 5), 20 \mathrm{~cm}$. from the centre. Observer's eye fixed upon a bead placed in front of the disc at that distance from the centre. Under these circumstances the white spot appears stretched out to a white band with indefinite beginning and end, which appears to be composed of several alternately lighter and darker portions of longer light internodes with shorter dark nodes. Whereas in the experiment of the black sector, the apparent angular magnitude increases with in creased speed of revolution, in this experiment the angular magnitudes of the nodes and internodes diminishes with in creased speed (or what amounts to the same ihing, with approximation of the observer's eye to the disc) and vice-versa

Charpentier explains this at first sight very puzzling relation by the following hypothesis, which is at the same time an ingenious application of a well-known physical principle to a hypothetical physiological wave transmission and a proof of the existence of the latter. Upon the incidence of the stimulus white, an oscillation of sensation is produced, of which the first or positive phase is white, the second or negative phase black; each phase has a duration of about $0.015 \mathrm{sec}$ - -i.e. the entire oscillation has a duration $t=0.03 \mathrm{sec}$, and a frequency $u \mathrm{cf} 33$ per sec. This much is demonstrated by the experiment of the black sector. Let us now suppose that the oscillation spreads from its origin in the organ of vision ${ }^{1}$ over the remainder of that organ, as an oscillation at one point of a pond spreads over the remainder of the pond. The problem is to determine the velocity of transmission $v$ and the wave length $l$ of this presumably propagated oscillation. This is done by Charpentier by the following physiological application of Döppler's principle re the apparent modification of sound-waves according as the distance hetween origin and ear is increasing or diminishing.

In accordance with a familiar relation, wave-length $l$ is equal to velocity $v$, multiplied by duration $t$, or $l=v t$. In accordance with Döppler's principle the apparent rise of tone or the apparent diminution of wave-length caused by the approximation of observer and wave origin, are such that $l^{\prime}=\left(v-v^{\prime}\right) t$, where $l^{\prime}$ is the apparent wave-length, and $v^{\prime}$ the velocity of approximation.

If we were debarred from measuring tones proceeding from stationary origins, we might nevertheless determine their wavelength and velocity by calculation from measurements of the apparent wave-lengths of tones proceeding from origins moving at different known velocities. From two equations, $l^{\prime}=\left(v-v^{\prime}\right) t$, $l^{\prime}=\left(v-v^{\prime \prime}\right) t$, we should have $t=\frac{l^{\prime}-l^{\prime \prime}}{v^{\prime \prime}-v^{\prime}}$ and its reciprocal, $n=\frac{v^{\prime \prime}-v^{\prime}}{l^{\prime}-l^{\prime \prime}}$ and (substituting $\frac{l}{v}$ for $t$ ) $v=\frac{l^{\prime} v^{\prime \prime}-l^{\prime \prime} v^{\prime}}{l^{\prime}-l^{\prime \prime}}$ and $l=\frac{l^{\prime} v^{\prime \prime}-l^{\prime \prime} v^{\prime}}{v^{\prime \prime}-v^{\prime}}$.

These are, in fact, the data experimentally accessible in the retinal phenomenon. We cannot (as far as is known at present) ineasure the velocity an 1 length of a retinal wave with stationary origin; we must determine these values from their apparent values with the wave-origin moving at different known velocities.

Practically the velosities $v^{\prime}, v^{\prime \prime}$, \&c., of the wave origin on the retina are easily adjusted ; the apparent wave-lengths $l^{\prime}, l^{\prime \prime}$, \&c., more or less accurately observed. Given the dimensions of the disc, its distance from the eye and its rate of revolution, the experimental velocities are easily calculated; similarly if the apparent dimensions on the disc of the nodes and internodes are accurately observed, the retinal wave-lengths corresponding with them can be accurately calculated. It is in this second determination that the chief experimental error can arise ; nevertheless, considering the original conditions of the problem and and that this is, in fact, the first time it has been approached

I It is essentially in lifferent whether we take orzan of vision to signify he retina or brain or retino-cerebral apparatus. It is convenient to refe measurements to th retinal wave-length.

NO. I 242 , VOL. 48 ] and solved by any method, the results given by Charpentier are, within limits, sufficiently demonstrative of the propagation of a retinal oscillation and of its approximate velocity and wavelengtb. He finds from a large number of measurements a vilocity between the limits of 53.8 and $90 \mathrm{~mm}$. per sec. (mean value, 72 ); a frequency between 28 and 54 (mean value, 36 ); a calculated wave-lengih on the retina of $2 \mathrm{~mm}$.; and a calculated wave-duration of $0028 \mathrm{sec}$.

Not the least satisfactory feature of these figures is that the value of the wave duration derived by the indirect method of this more difficult experiment, practically coincides with that derived from the simple and easy experiment of the black sector.

A third experiment of Charpentier's, although not precisely confirmatory of these, seems to stand in some relation to the negative seıni-vibration manifested as the black sector. A black disc with ojen sectors, revolving between the eye and a white sheet illuminated by direct surlight, gives rise to the sensation of a magnificent purple colour, when the rate of revolution is such that the eye receives between 40 and 60 stimuli per second, i.e. when each stimulus occurs during the negative phase of the preceding stimulus. Above 70 and below 30 stimuli per second the sheet appears white. The effect is very striking and very easily obtained ; in short, it is a "ladies' experiment"; it full explanation is a different matter, and far too uncertain for discussion in a short article.

A. D. W.

\section{THE POSITION OF SCIENTIFIC EXPERTS}

Fi ROM time to time it has been pointed out in these columns that the services rendered to litigators as such by so. called scientific experts is antagonistic to the pure spirit that should actuate men of science. For some years the position and character of the representalive of science in courts of justice has been acquiring interest, not only in England but elsewhere. In facl, a few years ago a Committee of the American Association for the Advancement of Science was appointed to consider the whole matter, but no report of their proceedings has yet been published. An excellent discussion of the subject, however, comes from America in the form of a reprinted lecture on "The Scientific Expert in Foreign Procedure," by Prof. C. F. Himes, which appears in the June number of the Journal of the Franklin In:titute. In order to direct the discussion, Prof. Himes first gives legal opinions as 10 the status of the expert. "Justice Miller," he says, "ex. hibited a plan of objection in a charge as follows :- 'My own experience, both in local courts and in the Supreme Court of the United States is, that when the matter in contest involves an immense sum in value, there is no difficulty in introducing any amount of expert testimony on either side.' Another judge, in a lecture upon medical expertism, gives a similar opinic n, that the ground of dissatisfaction in regard to medical testir.ony to both the professions of $1 \mathrm{aw}$ and medicine, are reducible to one-- that upon every conceivable issue expert opinions are procurable which sustain, or seem to sustain, the most contradictory views." But Prof. IIimes does not take a pessimistic view of the scientific expert. He is inclined to believe that :-

"The scientific expert is simply a product, and an extreme product, of an advanced and rapidly advancing civilisation. He was recognised in the germ, to be sure, by the old Roman law, and we may assume in all systems of jurisprudence; $l$ ut he has acquired an immensely increased importance, and a n:uch wider field and a far greater frequency of employment by the recent, and very recent, marvellous advances in the applicatiors of science-applications which have increased the sphere of things to be litigated about, which have introduced facts of an entirely new character to be adjudicated upon, to say nothing of the contribution that science has made, and is continually making, in many ordinary cases, of conclusive missing links of evidence which render decision previously uncertain, comfortably certain, and satisfactory.

"Now, one fact that seems latent in these expressions of the legal profession in regard to the scientific expert and almost the first that impresses is that in many respects he seems to be a positive annoyance to lawyers, and even to judges at times-a sort of intractable, incompatible, inharmonious factor, disturb. ing the otherwise smooth current of legal procedure; too important or necessary to be ruled out, too intelligent and disciplined mentally to yield without reason to ordinary rules 
and regulations of the court, with which he may not be familiar, and, at the same time, possessing an undoubted influence with a jury, that it is difficult to restrict by the established rules and maxims of legal procedure."

After a consideration of the circumstances that shape the reputation of the scientific expert with the bar, bench, and laity we read :--" In considering some of the sources of dissatisfaction with the scientific experts, perhaps one of the first to suggest itself, and one of the most prolific, is the vagueness of the legal definition of the term 'scientific expert' before alluded to, but which on more careful consideration might rather be termed vagueness and variableness of the standard. Definitions of things are of ideals, and consequently definition is followed closely by the statement that the thing defined is non-existent. The ideal circle is defined, so the ideal solid, the ideal liquid; these definitions are only approached, never realised. Degrees of approach constitute the differences. Practically the courts are limited to the best experts extant in any field, though they may at times fall far short of the ideal. But it is to be feared that in many cases the experts fall below a reasonable and possible standard, and far below the standard that would $l e$ fixed by scientific men themselves, as well a: below the exigencies of the case. This may easily ! e accounted for. A party presents a witness as an expert. The judge must pass upon his competency upon such examination as he can make. That decision, though not necessarily, nor even by unvarying practice, a matter of discretion, will not often be reviewed hy a superior court. Often, then, the best solution, certainly the easiest, seems to be to admit, even where there may be grave doubt as to qualification, and to throw the burden upon the jury, already overburdened with questions, which the theory of trial by jury assigns them, questions which they are not $\mathrm{q}$ alified to deal with, although they may be fully up to the average in general intelligence. At a time when experts were not much beyoad men in the ordinary avocations of life it may have been reasonable to require the jury to pass upon the "weight and credit to be given to evidence viewed in connection with all the circumstances,' b it under the changed circumstances of to-day, with experts of a character, and upon questions not dreamed of even a century ago, it seems to be straining a theory tos far to put upon an average jury the decision of so grave a question, as to the character of the expert, which the court may not be able to settle satisfactorily. But for the theory it would not be thought of, if a system of jurisprudence were now being devised. Now among the results incidental to a liberal interpretation of the term by the courts are many that are regarded as the gravest evils of expert testimony. With doors wide open to incompetent persons, very slight pecuniary advantage, and still more frequently the incidental benefit attributed to notoriety and advertisement would cause them to seek entrance. As a result differences of opinion may be anticipated where knowledge is wanting as a basis. Then, too, the number of such experts in any case will be greater. The cross-examination absolutely necessary to test such evidence must be exhaustive and tedious. Trials are prolonged. The expense of the administration of justice is increased without furthering its ends, and withal often with incidental discredit not only of the testimony of experts, but in a measure of the whole judicial procedure which is responsible for them; and the jury are often left in such a state of mental confusion that the evidence can only be weighed by counting the experts. Now the rule should tend toward a greater strictness in regard to the qualifications of experts, since the progress of science tends towards a greater degree of specialisation in study, and consequently to more minute and extended evidence on the whole, with greater restrictions on the range of best evidence of any particular expert. I science stood still, or if forensic science was confined at all ti.nes to the same old ground, everything would be settled, but as it is, the new points at issue continually arising make new demands upon experts, which there may be few at first qualified to meet. The introduction of advanced scientific expert testimony is then hardly a matter of option. It is forced upon the courts by the fact that science is just as ready in the bands of the unscrupulous and dishonest to perpetrate the most flagrant wrongs as to aid in their detection, and that there is no advance in science that is not as accessible to the enemies of society as well as to society itself.

"But another, even more prolific source of complaint than laxity of rule in the admission of experts, lies in the an omalous position of the expert in many respects, and under the best cil cumstances. He is legally a witness, an ordinary witress, but practically with extraotdinary functions and one loaded with extraordinary respcnsibilities, and one might add, frequently loaded with extraordinary, and teven absurd, expectations. As a witness he is subrcnaed by the sarre form, obliged to respond under the same penaliies, to take the same oath; is subject to the same rules and restrictions, and the same treatment in court. He has no higher claim upon the State, or upon the parties for his time or his private professional knowledge, which constitutes his livelihood. He receives, in most cases, to be sure, from the party calling him, a fee agreed upon between them, and certainly out of proportion to those of other witnesses, even if it is not professional in magnitude. He assists the side on which he is called in working up its case. He suggests the cross-exaurination of witnesses. He thus exhibits the character of a very willing u itness, of a well-paid witness, combined with a great deal of the advocate. Now he cannot be held responsible fur this position, but the system of jurisprudence, which not simply permits it, which has not simply taken him, but has forced him in, and which, apparently cognizant of all, seems only able to originate complaints, rather than to provide a different character for him; for there seems, indced, in many of the adverse criiicisms of experts, to be only a confession of weakness, rather than a disposition earnestly to cons:der the whole question with a view to the radical remedy of the evils. The human nature of the judge is recognised and provided against. Every safeguard is thrown around him to protect him from bias, or possible suspicion of bias, which would be almost as bad. The jury is selected so as to be free from bias, and is protected as well. Oiher witnesses are not expected to take the part the scientific expert is almost compelled to take. In fact, if deliberately planned, there could hardly be a network of conditions devised, calculated to produce so many of the evils of scientific expert testimony complained of, or to cloud this testimony of highest intrinsic value, having the highest degree of certainty, and in a field altogether its own."

"But in regard to the charge of bias," Prof. Himes afterwards goes on to say, "it may be admitted that the scientific expert may at times be biased, but that is only admitting that he is made of the same clay as other men. The bias, if not produced hy the call, would certainly not be more of a reflection on his character than upon the system of jurisprudence which renders a call based upon bias not only possible, but almost necessary, and which provides no other method for the intro. duction of scientific testimony. But bias may be in nowise incidental to the call. It may be a purely scientific bias, due to some peculiar view or theory. No kind of training will fortify a man against bias at all points. In his laboratory, in conducting his investigations, the scientific expert may keep himsel free from bias. The judge upon the bench is free from bias by habit, ra her than by conscious effort. But even the judge, placed in some novel position of great responsibility, which this judicial habit does not fit exactly might lapse into a bias.

"The criticism due to differences of opinion frequently ex. hibited by scientific experts can hardly be regarded as a serious matter by a profession characterised by differences of opinions on all conceivable points; the only settled opinions known to it being those of the court of last resort, which even claims the privilege occasionally of reversing itself. Differences of opinion among scientific experts are often doubtless due to differences in scientific character, resulting from the loose rule of admission. But there may still be honest differences between experts of highest character. I think such, however, it will be found, are rarely in regard to well-established facts, but oftener in regard to probable inferences from facts, whilst entire agreement would be marvellous in matters of theory and speculation. Courts and at torneys do not discriminate sufficiently between well-established scientific facts and scientific theories. Some of the most recent and far-reaching decisions of our highest tribunals have a basis of theory rather than of fact."

This leads to a point which we have always insi-ted upon, namely, that a scientific expert should not be called and sub. sidised by a particular side, but should be appointed by the judge or jury. To quote $P_{1}$ of. Himes :-

"Many of the most objectionable features of the expert witness originate in the mode of his entrance into court, and it is an allowable question, whether any modification could be made in the calling of the witness. Among the reports one judge ex- 
presses the npinion that, 'expert witnesses ought to be selected hy the court, and should be impartial as well as learned and skilful. A contrary practice, however, is now prohally too well established to allow the more salutary rule to be enforced. Another judge suggests that the law should be so changed 'that th:s class of witnesses should be selected by the court, and that this should be done wholly independent of any nom: nation, recsmmendation, or interference of the parties, as much so to all intents as are the jurors.' This would not make ex perts amici curice any more than before, for all witnesses should be regarded in that light, but it would be a provision rather to preserve that character to them, coupled as it is with a recom mentation as to compensation, so intimately connected $w$ ith it. It is not the fact of extra compen:ation, or that the compensation is paid by the party benefited by his testimony, that creates the unfavourable impression. The o:her witnesies are friends of the court, by whatever pa-ty they may be called, they stand upon the same fosting as to pay; but here is a witness who is paid according to a private agreement, by one of the parties ; the amount is their own private arrangement on which the court is not consulter, over which the court has no control, a circumstance that imparts to him, in high degree, the characler of a friend of one of the parties; and these facts as to compensation are ofien elicited at a time, and in a way, calculated to impair otherwise valuable testimony in the minds of the jury.

"Ry far the best plan seems to be that adopted in the Imperial Courts of Germany. For certain matters and lines of busine.s permanent experts are appointed by the State, but they are nist regarded as officers, but as employ's for the time being. They have no official title, nor regular salary. The payment they receive is not enough to support them, but barely compensates them for their loss of time. For most cases the expert is appointed by the particular judge in the case, often on the demand of one or the other or both parties, but the choice of the expert lies within the discretion of the judge. He may appoint any man whom both parties sugrested, or may also appoint a third man no: suggested hy either, but if both paries unite on one man he must listen to his testimony. If a question is involved for which regular legal experts are provided, these need only be or can he appointed. The qualification; for such a regular expert are that he should follow that particular p:ofession or line of business habitually, and for the purp sse of earning his living. The number of experts in a case is not limited by law, it rests with the discretion of the judge. The status of the expert in court is almost analogou; to other witnesses, but it is not a civic duty, as with witnesses, to give evidence in court except where a profession is followed publicly and for a livelihood. The text of his oath before giving testimony is different from that of an ordinary witness; and he need not be sworn at all if $b$, th parties unite in dispensing with such gualification."

If a similar system were followed in England the testimony of scientific experts would be regarded with a little less suspicion than it is at present. Only by s me such mexns can technicsl evidence of a wholly disinterested character be obtained.

\section{SCIENCE CLASSES IN CONNECTION WITH THE LONDON COUNTY COUNCIL.}

THE Technical Education Board of the London Counly Council has issued a series of Regulations with regard to the administration of grants to science classes. All the preseribed conditions tend to make the instruction efficient and develop technical education in the right direction. The following are those that refer to the manner in which various classes must be conducted :-

(t) That as a condition of aid being granted by the Board for the teaching of chemistry, physics, mechanics, and botany, it wil be regarded as indispensable that provision should be made, to the satisfaction of the Board, not only for the experimenial illus. tration of the lectures or class teaching, but fur experimental work by the students themselves, either in lab ratories bel unging to the institution or, where this cannot be arranged, in the laboratorie; of some neighbouring institution with which the class should be associated ; and ev.ry lecture must be followe by at least one hour's practical work on the same evening, or some other evening in the same week.

(2) Thut with reyard to classes in the subjects comprised in the Science and Art Department Directory which are more s:rictly NO. 1242 , VOL. $4 \delta]$ to be included under the head of technology, viz. building construction and drawing, machine construction and drawing, steam and the steam-engine, navigation and navai architecture, it be required, as a rule, that such classes be taught by teachers having a practical acquaintance with the industries to which they refer; provited that, in the case of teachers who have already succes: fully tatuht such classes, it shall be open to the Board, on being satisfied of the sufficiency of the qualifications, to make exception; in particular cases. No grant will be given fo- classes in agriculture or mining.

(3) That for classes in geology and mineralogy suitable museum specimens be provided and examined by the pupils, and for classes in machine drawing a suitable collection of models and parts of actual machines be provided.

(4) That in the teaching of mathematics, pracicai geometry, building construction, machine drawing, naval architecture, navigation and nautical astronomy, "home work" be made an important feature, and that the students' work be examined and correcied by the teacher out of class hours.

(5) That in all practical laboratory classes, and in classes on mathematic:, pracical yeometry, building con truc ion, mactrine drawing, naval architecture, navigation and nautical astronomy, not more than twen'y stu lents shall be under the charge of one teacher at the same time, but where more than one teacher is present during the whole meeting of the class the number of students may be increased in proportion to the number of teachers.

(6) That in all subjects there be a sufficient supply of appara:u; and $\mathrm{ma}^{+}$erials for efficient teaching, and that such apparatus and materials be $t$ flectively used.

(7) That no payment be made on account of pupils who, in the opinion of the Board, may not reasonably be expected $t$, profit by the teachin $r$ provided (e.g. pupils in navigation or nau ical a-tronomy, or in the advanced stage of theoretical or applied mechanics who have insuff sient knowleilge of mathe matics; those in building construction or machine drawing who have no knowledye of elementary mechanics, \&c.).

The Board is prepared to consider applicalions for assistance to erect laboraturies and provide $t h=$ necessary equipment. It will also make grants in aid of the purchase of apparatus for science teaching. With so many advantages, technical education in the administrative county of London should grow apace.

\section{UNIVERSITY AND EDUCATIONAL INTELLIGENCE.}

THE following is the list of candidates successful in the competition for the IVhitworth Szholarships and Exhibitions, I893:- Scholarships (tenable for three years, having an annual value of $(125)$ :- William Hamilton (Glaigo."), Tohn G. Longbottom (Keighle)), Arthur E. Malpas (London), Richard J Durley (I.ondon); Exhibitions (tenable for one year, having a value of $f_{50}$ ): - Charles F.S ith (Glasgow), John Ball (Derby), William Buchan (Glasgow), John B. Chambers (London), Henry J. Loveridge (Southsea, Portsmouth), William F. Ireland (Glasgow), George W. Fearnley (Shipley), Oliver Styles (Edinburgh), George M. Russell (Portsmouth), Alexander A. Jude (Huli), Elward R. Amor (Devonport), Josepl Jeffery (Birmingham), Paul J. Reynolds (Plumstead, Keni), Thomas Pilkington (London), Richard Reynolds (Cardiff), George Wilson (Sheffield), Walter O. Hammant (Plumstead, Kent), John Orr (Airdrie), William I. Chubb (Londori), Henry Smith (Brighton), Frederick D. Green (Wanstead, Essex), John Powell (Crewr), James H. Hardy (Woodley, near Stockporl), James H. Shepherd (Swindon), Herbert Thompson (Sheffiell), Evan Stevens (Swindon), Henry E. Morrall (Wolverton), Herbert Bates (Manchester), Charles H. Hill (Stratford, London), William F. Massey (Newport, Salop).

The Scholarships Committee of the 185 I Exhibition Science Scholarships has issued a list of appointments for 1893 . Four scholarships awarded in $189 \mathrm{I}$ have been renewed for a thirc year in order to permit the holders to complete their investiga tions. These scholars are James H. Gray, John Joseph Sudborough, Harry Ingle, and Thomas Ewan. The following scholars of 1892 have had their scholarships renewed for a second year:--Andrew John Herbertson, James Blacklock IIenderson, John Macdonald, Lionel Sime n Marks, George Lester Thomas, Hurold Hart Mann, James Terence Conroy, 